\title{
Bacillus anthracis Lethal Toxin Disrupts TCR Signaling in CD1d-Restricted NKT Cells Leading to Functional Anergy
}

\author{
Sunil K. Joshi', Gillian A. Lang', Jason L. Larabee, T. Scott Devera, Lindsay M. Aye, Hemangi B. Shah, \\ Jimmy D. Ballard, Mark L. Lang*
}

Department of Microbiology and Immunology, University of Oklahoma Health Sciences Center, Oklahoma City, Oklahoma, United States of America

\begin{abstract}
Exogenous CD1d-binding glycolipid ( $\alpha$-Galactosylceramide, $\alpha-\mathrm{GC}$ ) stimulates TCR signaling and activation of type- 1 natural killer-like T (NKT) cells. Activated NKT cells play a central role in the regulation of adaptive and protective immune responses against pathogens and tumors. In the present study, we tested the effect of Bacillus anthracis lethal toxin (LT) on NKT cells both in vivo and in vitro. LT is a binary toxin known to suppress host immune responses during anthrax disease and intoxicates cells by protective antigen (PA)-mediated intracellular delivery of lethal factor (LF), a potent metalloprotease. We observed that NKT cells expressed anthrax toxin receptors (CMG-2 and TEM-8) and bound more PA than other immune cell types. A sub-lethal dose of LT administered in vivo in C57BL/6 mice decreased expression of the activation receptor NKG2D by NKT cells but not by NK cells. The in vivo administration of LT led to decreased TCR-induced cytokine secretion but did not affect TCR expression. Further analysis revealed LT-dependent inhibition of TCR-stimulated MAP kinase signaling in NKT cells attributable to LT cleavage of the MAP kinase kinase MEK-2. We propose that Bacillus anthracis-derived LT causes a novel form of functional anergy in NKT cells and therefore has potential for contributing to immune evasion by the pathogen.
\end{abstract}

Citation: Joshi SK, Lang GA, Larabee JL, Devera TS, Aye LM, et al. (2009) Bacillus anthracis Lethal Toxin Disrupts TCR Signaling in CD1d-Restricted NKT Cells Leading to Functional Anergy. PLoS Pathog 5(9): e1000588. doi:10.1371/journal.ppat.1000588

Editor: John A. T. Young, The Salk Institute for Biological Studies, United States of America

Received June 24, 2009; Accepted August 24, 2009; Published September 25, 2009

Copyright: (C) 2009 Joshi et al. This is an open-access article distributed under the terms of the Creative Commons Attribution License, which permits unrestricted use, distribution, and reproduction in any medium, provided the original author and source are credited.

Funding: This work was supported by a pilot award to M.L.L. as part of NIH grant 5 U19 Al062629-05 (PI: Dr. M. Coggeshall, Oklahoma Medical Research Foundation) and NIH RO1 Al078993 to M.L.L. The funders had no role in study design, data collection and analysis, decision to publish, or preparation of the manuscript.

Competing Interests: The authors have declared that no competing interests exist.

* E-mail: mark-lang@ouhsc.edu

9 These authors contributed equally to this work.

\section{Introduction}

CD1d-restricted Type I NKT cells are central regulators of adaptive immune responses [1]. NKT cells can be activated with exogenous CDld-binding glycolipid antigen $(\mathrm{Ag})$ to boost humoral immunity and prime CTL responses specific for co-administered Ag $[2,3,4]$. The mechanisms by which NKT cells enhance antibody $(\mathrm{Ab})$ responses are unclear but involve cognate and non-cognate interactions between NKT cells and B cells $[5,6,7]$. The interactions of dendritic cells (DG) and NKT cells have been studied more extensively. NKT cells can drive DC maturation and induction of tumor-specific CTL [8,9], a mechanism likely important for NKT-enhanced tumor rejection $[4,10]$. There is also evidence for increased priming of Th responses as a result of NKT activation suggesting an important contribution to the initiation of adaptive immunity [4].

NKT cells contribute to the adaptive (and protective) immune response to bacterial, viral and potentially parasitic infections $[11,12,13]$. However, the effects of pathogen-derived virulence factors including bacterial exotoxins on NKT function have received little attention. The Bovine Calmette-Guerin (BCG) bacterium, bacterial LPS and CDld-binding glycolipids can induce a state of non-responsiveness or anergy in NKT cells although it is not appreciated whether this is reflective of pathogen-derived products subverting the host immune response and/or the host limiting the production of tissue-damaging NKT products following infection [14,15].

Bacillus anthracis lethal toxin (LT) is a paradigm for virulence factors that strongly subvert and suppress host immunity during disease $[16,17,18]$. Anthrax involves severe and extensive bacteremia with the organism growing to very high numbers $\left(>10^{8}\right.$ organisms $\left./ \mathrm{ml}\right)$ in the bloodstream. This high level of growth is thought to be possible because LT severely cripples the host immune system. Thus, the mechanism by which LT intoxicates cells has been the subject of intense study. In order to disrupt target-cell function, protective antigen (PA) interacts with specific cell surface receptors, forms a heptameric structure that is bound by LF, and the complex is endocytosed into the cytosol [19]. Once delivered by PA into the cell, LF cleaves and inactivates MAPKKs, such as MEK-2, leading to disruption in MAPK signaling [20]. Yet, despite these many important advances in understanding the mechanism of cellular intoxication by LT, little is known about the specific types of immune cells targeted by this toxin during disease.

In the present study, we tested the hypothesis that a sub-lethal dose of LT administered in vivo could impact murine NKT cell function. We report that NKT cells express anthrax toxin receptors and bind PA to a greater degree than other types of immune cell. LT also causes reduced expression of several activation-inducing molecules on NKT cells. Furthermore, LT 


\section{Author Summary}

The bacterium Bacillus anthracis is the causative agent of anthrax infection. Anthrax is a life-threatening disease caused by inhalation or ingestion of spores, or transmission through wounds and abrasions. The bacterium secretes toxins, proteins that enter numerous cell types in an infected individual altering their function and contributing to the disease process. Consequently, we and other researchers are dedicated to identifying cells affected by anthrax toxins and to understanding the implications for the function of those cells. We have observed that anthrax toxins adversely affect a type of cell in the immune system known as a natural killer-like T (NKT) cell. NKT cells are found in the bone marrow, blood, spleen, lymph nodes and liver and are required for optimal immune responses. We report that anthrax toxins effectively shut down NKT cells, preventing them from functioning normally. We propose that this has serious consequences because anyone infected with Bacillus anthracis will be less able to mount an immune response against it.

treatment inhibited NKT activation by CDld/glycolipid complexes as evidenced by reduced cytokine secretion. These results indicate that one of the immune evasion/suppression strategies employed by $B$. anthracis involves reduced NKT activation.

\section{Materials and Methods}

\section{Toxin expression and purification}

Histidine-tagged PA and LF were expressed separately in competent BL21 Escherichia coli (Invitrogen, Carlsbad, CA) transformed with the pET15b-rPA, pET15b-rLF and pET15brLF ${ }^{\mathrm{H} 690 \mathrm{C}}$ plasmids respectively (gifts from Dr. J. Collier, Harvard Medical School). PA and LF were then purified from bacterial lysates using standard methods also described previously [21]. In brief, PA and LF purification was achieved using a $5 \mathrm{ml}$ HisTrap FF affinity column (GE LifeSciences, Piscataway, NJ). LPS contamination was removed by from purified PA and LF using an EndoTrap Red LPSbinding affinity column (Lonza, Walkersville, MD). The concentration of residual endotoxin was determined using the Limulus Assay, which has a sensitivity of 0.06 Endotoxin Units $/ \mathrm{ml}(6 \mathrm{pg} / \mathrm{ml})$ (Lonza). The final preparation used for this study contained $40 \mathrm{ng} / \mathrm{ml}$ LPS in the PA and was below the limits of detection for the LF. No more than 4 ng LPS was administered to each mouse in experiments described herein.

\section{Mice}

Female C57BL/6 mice were purchased from the National Cancer Institute (Bethesda, MD) and used for experiments at 6$10 \mathrm{wk}$ of age. $\mathrm{J} \alpha 18^{-/-}$mice (also known as $\mathrm{J} \alpha 281^{-/-}$) on the C57BL/6 genetic background were obtained from Dr. M. Kronenberg (La Jolla Institute for Allergy and Immunology) with kind permission from Dr M. Taniguchi (RIKEN Institute, Japan). The Institutional Animal Care and Use Committee at the University of Oklahoma Health Sciences Center approved all procedures described herein.

\section{Toxin administration}

$200 \mu \mathrm{g}$ of lethal toxin (1:1 molar ratio of PA and LF) in sterile endotoxin-free PBS was administered i.v. by para-orbital injection whilst mice were anesthetized using $4 \%$ vaporized isofluorane. Mice were euthanized 4 days after toxin injection. Spleen, liver, thymus and $\mathrm{LN}$ were harvested.

\section{Cell isolation}

Single cell suspensions were prepared from the harvested tissue by mechanical disruption. Erythrocytes were removed by lysis with ammonium chloride buffer $\left(0.16 \mathrm{M} \mathrm{NH}_{4} \mathrm{Cl}, 0.17 \mathrm{M}\right.$ Tris- $\mathrm{HCl}$, pH 7.4). Cells were washed in RPMI 1640 and cell number and viability were assessed by trypan blue exclusion. Hepatic lymphocytes were obtained from hepatocytes by percoll density gradient centrifugation.

\section{Antibodies and fluorochromes}

Allophycocyanin (APC-) or PE-conjugated CDld tetramer loaded with $\alpha$-GC was obtained from the NIAID tetramer facility (Emory University, Atlanta, GA). 2.4G2 Fc-blocking mAb was purchased from BioXcell (Lebanon, NH). Anti-CD49b, -CD3, -CD28 and -TCR $\beta$ mAbs were purchased from BD Biosciences (Palo Alto, CA). Anti-Erk1/2 and anti-phospho-Erk1/2 polyclonal Abs were purchased from Cell Signaling Technology (Worcester, MA). Anti-MEK-2 N-terminal polyclonal Ab was purchased from Santa Cruz Biotechnology (Santa Cruz, CA). Anti-GAPDH mAb was purchased from Abcam Inc. (Cambridge, MA). All other antibodies were from e-Bioscience (San Diego, CA). Alexa 647-conjugated PA was produced in house using an Alexa labeling kit according to manufacturer's instructions (Invitrogen, Carlsbad, CA).

\section{Flow cytometry}

The 2.4G2 mAb was added to cell suspensions at a final concentration of $20 \mu \mathrm{g} / \mathrm{ml}$. Cells were then incubated at room temperature for $1 \mathrm{~h}$ with a 1:250 dilution of CDld tetramer and appropriate mAbs at a 1:100 -200 dilution. Unbound mAbs and tetramer were removed by washing cells three times in PBS. Cells were fixed with $1 \% \mathrm{v} / \mathrm{v}$ p-formaldehyde in PBS and samples were then analyzed by flow cytometry (FACSCalibur, Becton Dickinson, Palo Alto, CA.).

\section{In vitro NKT stimulation}

Four similar approaches were taken to stimulate NKT cell TCR signaling. (i) Splenocytes were obtained from mice treated with LT in vivo. Splenocytes were then stimulated in vitro with $\alpha-G G$ (BioMol, Cambridge, MA) at a final concentration of $50 \mathrm{ng} / \mathrm{ml}$. After 24 and $48 \mathrm{~h}$, supernatants were collected and stored at $-80^{\circ} \mathrm{C}$. (ii) Splenocytes were obtained from NKT-deficient $\mathrm{J} \alpha 18^{-\prime}$ mice and in vitro-expanded NKT cells were obtained from splenocytes of C57BL/6 mice using a modified version of the method reported by the Taniguchi laboratory [22]. NKT cell purity as defined by CDld tetramer binding was $85 \%-96 \%$ in the experiments reported herein. $\mathrm{J} \alpha 18^{-/-}$splenocytes and C57BL/6 NKT cells were treated for $1 \mathrm{~h}$ with PBS or LT at a final concentration of $1 \mu \mathrm{g} / \mathrm{ml}$. After washing the PBS-treated and LTtreated cells were cultured separately or co-cultured (splenocytes plus NKT cells) in the absence or presence of $\alpha$-GC at a final concentration of $50 \mathrm{ng} / \mathrm{ml}$ for $48 \mathrm{~h}$. The supernatants were then collected and stored at $-80^{\circ} \mathrm{C}$ until required. IL-4 and IFN $\gamma$ concentrations in the supernatants were then determined by Multi-Plex cytokine analysis according to manufacturer's instructions using the Bio-Plex assay system (Bio-Rad, Hercules, CA). (iii) Anti-NK1.1-enriched NKT cells (52\% pure) were treated with PBS or LT in vitro and then cultured on 96 well plates coated with anti-CD3 $\mathrm{mAb}$ at a coating concentration of $10 \mu \mathrm{g} / \mathrm{ml}$ and with media containing $10 \mu \mathrm{g} / \mathrm{ml}$ anti-CD28 mAb. After $48 \mathrm{~h}$, cell culture supernatants were collected for analysis. In these assays, the remaining cells were tetramer ${ }^{-} / \mathrm{TCR}^{+} / \mathrm{NK} 1.1^{+}$cells, NK cells and there were no detectable $\mathrm{T}$ cells (iv) Anti-NK1.1-enriched 
NKT cells were treated with PBS or LT and then coated with anti$\mathrm{CD} 3 \mathrm{mAb}$ at $4^{\circ} \mathrm{C}$ before washing and cross-linking the bound $\mathrm{Ab}$ by addition of an anti-Armenian Hamster IgG solution (Rockland Inc., Rockland, MD) at $37^{\circ} \mathrm{C}$. After 5 minutes cells were pelleted by a $7 \mathrm{~s}$ micro-centrifuge pulse. Pellets were immediately resuspended in ice-cold lysis buffer containing: 1.0\% v/v NP40; a protease inhibitor cocktail (Roche Systems Inc., Pleasanton, California); $4.0 \mathrm{mM} \mathrm{Na}_{3} \mathrm{VO}_{4}$ and $2.0 \mathrm{mM} \mathrm{NaF}$. After incubation on ice for $30 \mathrm{~min}$, lysates were then clarified by centrifugation at 13,000 RCF for $10 \mathrm{~min}$ at $4^{\circ} \mathrm{C}$. Supernatants were collected and stored at $-20^{\circ} \mathrm{C}$ until required.

\section{Immunoblot}

Cell lysates were subjected to SDS-PAGE under reducing conditions and proteins were then transferred to nitrocellulose membranes using a Bio-Rad semi-dry blotter. Membranes were blocked with $5 \% \mathrm{w} / \mathrm{v}$ non-fat dry milk in PBS containing $0.5 \% \mathrm{v} / \mathrm{v}$ TWEEN-20 for $1 \mathrm{~h}$ before addition of primary $\mathrm{Ab}$ at a $1 \mu \mathrm{g} / \mathrm{ml}$ final concentration and incubation overnight at $4^{\circ} \mathrm{C}$. Membranes were washed 6 times in PBS before incubation with HRP-conjugated secondary Ab in 3\% milk in PBS containing $0.05 \% \mathrm{v} / \mathrm{v}$ TWEEN-20 and further washing. ECL Plus reagent (GE Healthcare, Piscataway, $\mathrm{NJ}$ ) was used to detect membrane-bound $\mathrm{Ab}$ and imaged using Blue Basic Autoradiography Film (ISC BioExpress, Kaysville, UT).

\section{Results}

\section{Protective antigen targets NKT cells}

Hepatic lymphocytes, splenocytes, lymph node cells and thymocytes were obtained from C57BL/ 6 mice. The cells were stained with $\alpha$-GC-loaded CDld-tetramer and anti-TCR $\beta \mathrm{mAb}$ to distinguish between type I NKT cells $\left(\alpha-G C / C D 1 d\right.$ tetramer ${ }^{+} /$ TCR $\left.\beta^{+}\right)$, T cells $\left(\alpha-G C / C D l d\right.$ tetramer $\left.{ }^{-} / \mathrm{TCR} \beta^{+}\right)$and non-

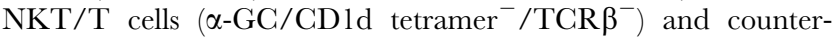
stained with Alexa647-conjugated PA (Figure 1A). We observed that PA bound all $\alpha$-GC/tetramer/TCR $\beta^{+}$cells and did so to a greater extent than $\mathrm{TCR} \beta^{+} \mathrm{T}$ cells and non-T/NKT cells represented mainly by $\mathrm{B}$ cells and dendritic cells. The binding of PA to all cells could be saturated and then competed out with a 10fold molar excess of unlabeled PA indicating expression of specific receptors (Figure 1B). The Kd for binding of PA to NKT cells was approximately $20 \mathrm{nM}$ which is consistent with the observed expression of both known PA receptors Tumor Endothelial Marker-8 (TEM-8) and Capillary Morphogenesis protein-2 (CMG-2) with reported affinities in vitro of $130 \mathrm{nM}$ and $0.17 \mathrm{nM}$ respectively [23]. Purified splenic NKT cells were shown by immunoblot to express the $60 \mathrm{kDa}$ and $45 \mathrm{kDa}$ splice variants of TEM-8 and the $55 \mathrm{kDa}$ form of CMG-2 (Figure 1C) at a greater abundance, relative to splenocyte lysates. The stronger signal obtained with the NKT lysates as compared to the splenic lysates is consistent with the differential expression detected by flow cytometry. These data show that NKT cells express higher amounts of the PA receptors than other hematopoietic cell types, suggesting NKT cells may be more susceptible to the effects of LT than other cell types.

\section{Lethal toxin alters expression of several NKT cell surface markers}

C57BL/6 mice were treated with a sub-lethal dose of LT and splenocytes were harvested $4 \mathrm{~d}$ later (Figure 2). We observed that LT treatment had no effect on binding of $\alpha$-GC/CDld tetramers or anti-TCR $\beta \mathrm{mAb}$, indicating that expression of the invariant V $\alpha 14 / J \alpha 18$ TCR was not affected by LT. Similarly, TCR $\beta$ expression on $\mathrm{T}$ cells was not affected (Figure 2A). LT induced considerable splenomegaly increasing the total cellular yield approximately two fold but had only a small effect on the frequency ( $25 \%$ increase) of NKT cells in the spleen (Figure S1). The increase in splenic NKT cell numbers could be caused by recruitment from other locations, proliferation of splenic NKT cells or a combination of both effects.

Several NK- and NKT-associated activating and inhibitory receptors as well as other markers of NKT activation were then examined (Figure 2B). LT treatment resulted in decreased expression of the activation molecule NKG2d but had no effect on NK1.1 expression. The effect on NKG2D expression was specific to NKT cells since toxin did not alter NKG2D expression by NK cells in $\mathrm{C} 57 \mathrm{Bl} / 6$ or $\mathrm{J} \alpha 18^{-/-}$mice (Figure S2A). Furthermore, active LT was required since a function-deficient mutant LT $^{\text {H690C }}$ did not affect NKG2D expression by NKT cells (Figure S2B). A minor increase in the expression of the inhibitory LY49 receptors was observed following treatment with active LT (Figure 2B). There was also a small increase in the expression of CD62L and a substantial decrease in the expression of CD69 (Figure 2B). NKT cells have an innate 'memory/activated phenotype' and unlike naïve $\mathrm{T}$ cells $\left(\mathrm{CD} 69^{\mathrm{lo}} / \mathrm{CD} 6 \mathrm{~L}^{\mathrm{hi}}\right.$ ) are constitutively CD69hi CD62L ${ }^{\text {lo }}$ [24]. Changes in NKG2D expression by splenic NKT cells were not observed $3 \mathrm{~h}, 6 \mathrm{~h}$ and $14 \mathrm{~d}$ after LT in vivo administration (Figure S3A). In contrast, although splenocytes had returned to the pre-treatment phenotype by $14 \mathrm{~d}$, LN cells still had reduced NKG2D expression (Figure S3B). Thymic NKT cells were also largely NKG2D ${ }^{+}$indicating that the primary target of the toxin was NKT cells in the periphery rather than developing NKT cells in the thymus (Figure S3C). We also tested the effect of the toxin components PA and LF individually and did not observe splenomegaly, changes in NKT frequency, tetramer binding, or expression of TCR $\beta$ and NKG2D (data not shown). In further controls we determined that $20 \mathrm{ng}$, and $4 \mu \mathrm{g}$ of LPS administered by the i.v. route did not result in reduced NKG2D or CD69 expression by NKT cells at $96 \mathrm{~h}$ as observed for LT (data not shown). This demonstrates that any residual LPS (estimated at no more than $4 \mathrm{ng}$ per dose) in the LT preparation does not account for the observed effects of LT on NKT cells.

The overall effect of LT treatment therefore appears to be a shift from the memory/activated phenotype to that of an anergic NKT cell as evidenced by loss of NKG2D and CD69. In contrast, another study showed that LPS-induced anergy does not involve loss of CD69 by NKT cells and NKG2D expression was not examined [15]. However to the best of our knowledge these findings are the first to demonstrate that a bacterial exotoxin can alter the activation potential of NKT cells and it seems the mechanism is different from that employed by LPS.

\section{NKT cells from toxin-treated mice are viable and non-apoptotic}

We assessed Annexin $\mathrm{V}$ versus 7-AAD (7-amino-actinomycin D) staining in $\alpha$-GC/CDld tetramer ${ }^{+} / \mathrm{TCR}^{+}$NKT cells which allows one to distinguish live, non-apoptotic cells $\left(\mathrm{AnnV}^{-} / 7\right.$ $\left.\mathrm{AAD}^{-}\right)$from early apoptotic $\left(\mathrm{AnnV}^{+} / 7-\mathrm{AAD}^{-}\right)$, late apoptotic $\left(\mathrm{AnnV}^{+} / 7-\mathrm{AAD}^{+}\right)$and necrotic $\left(\mathrm{AnnV}^{-} / 7-\mathrm{AAD}^{+}\right)$cells (Figure 3, left panels). We did not observe any changes in binding of Annexin $\mathrm{V}$ or uptake of 7-AAD by NKT cells following toxin treatment. We examined expression of the programmed-death-1 molecule (PD-1) recently reported to be required for NKT anergy induction [25]. LT treatment did not affect NKT expression of PD-1 (Figure 3, middle panels). We also assessed expression of Fas which was not altered by treatment with the toxin (Figure 3, right panels). This is in contrast to BCG which induces Fas up-regulation and 
A

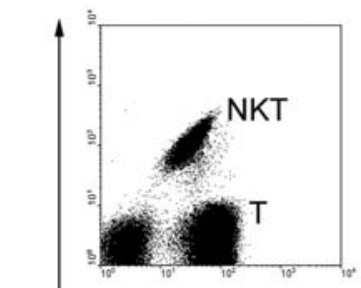

Spleen

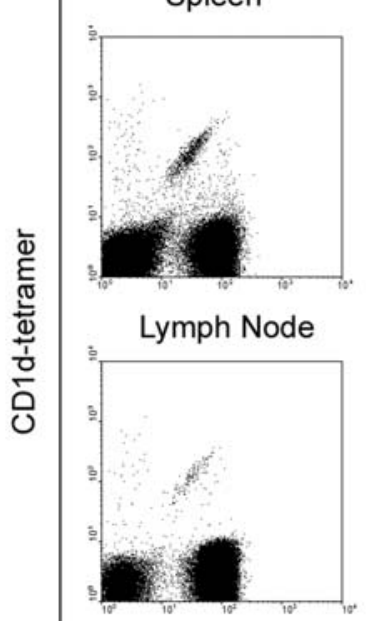

Thymus

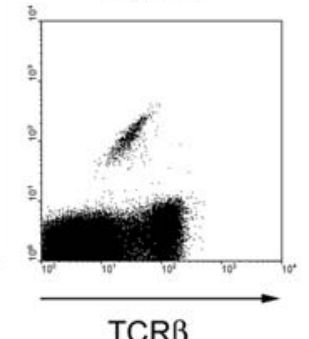

TCR $\beta$
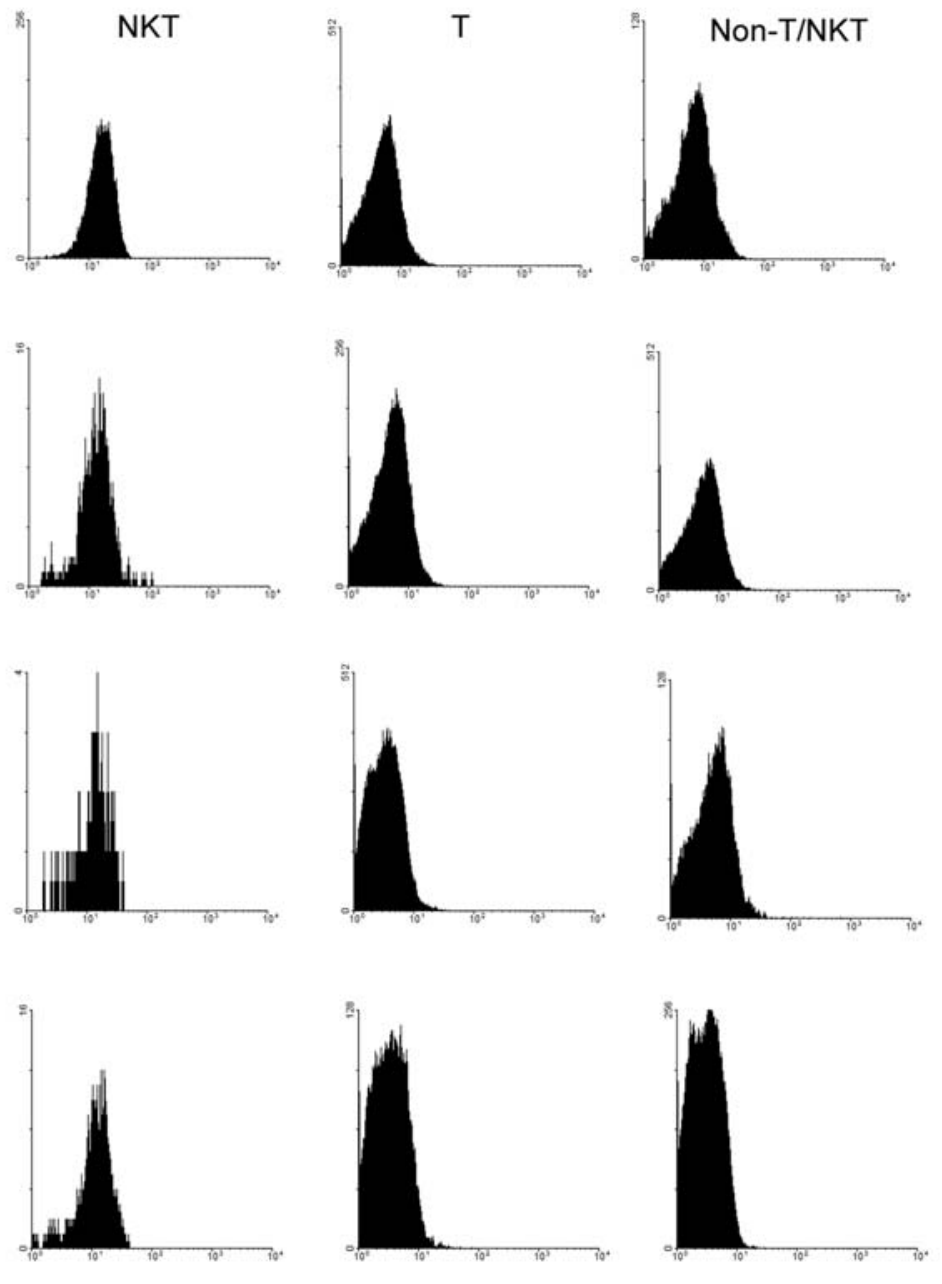

PA
B

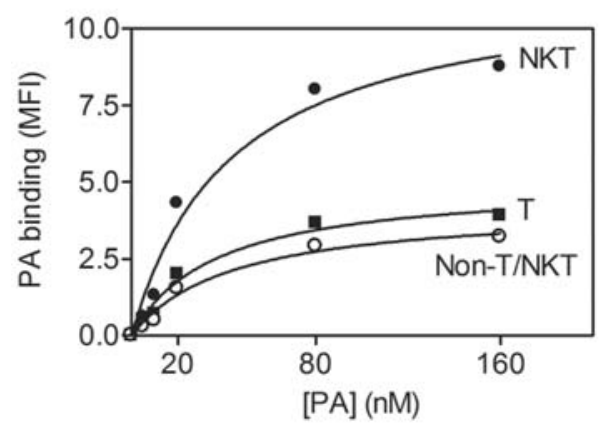

C

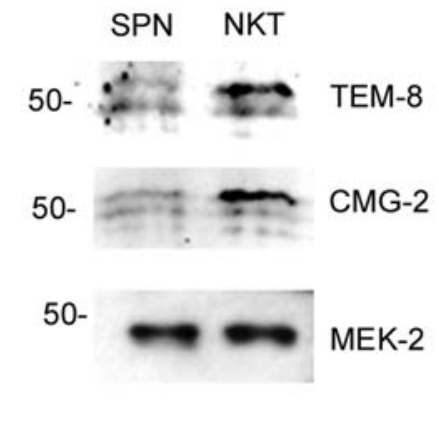

Figure 1. PA binds to NKT cells. Hepatic lymphocytes, splenocytes, lymph node cells and thymocytes were obtained from C57BL/6 mice. A Cells were stained with $\alpha$-GC-loaded PE-CD1d tetramer and FITC-anti-TCR $\beta$ mAb to distinguish NKT cells, T cells and non-T/NKT cells. Samples were also counter-stained with Alexa647-PA to detect PA-binding proteins. Histograms show PA binding to each cell type. B Splenocytes were stained as described and with the concentrations of Alexa647-PA indicated. Graph shows effect of PA concentration on binding to different cell types. The histogram shows the effect of unlabeled PA on binding of Alexa647-PA. Filled histogram=no PA, continuous line=Alexa647-PA, dotted line = Alexa647-PA plus unlabeled PA. The data in A for spleen, lymph node and thymus are representative of three independent experiments. Binding of PA to hepatocytes in A and the dose response curve in B are from a single experiment. C Cell lysates were prepared from whole splenocytes (left lane) and hepatocytes (middle lane) of C57BL/6 mice (middle lane). NKT cells were enriched from the spleens of C57BL/6 mice and expanded in vitro for $5 \mathrm{~d}$ until $96 \%$ pure (right lane). Cell lysates were resolved by SDS-PAGE and examined by immunoblotting for the anthrax toxin receptors TEM-8 and CMG-2 and the anthrax toxin intracellular target MEK-2 which serves as a loading control. doi:10.1371/journal.ppat.1000588.g001 
B

A

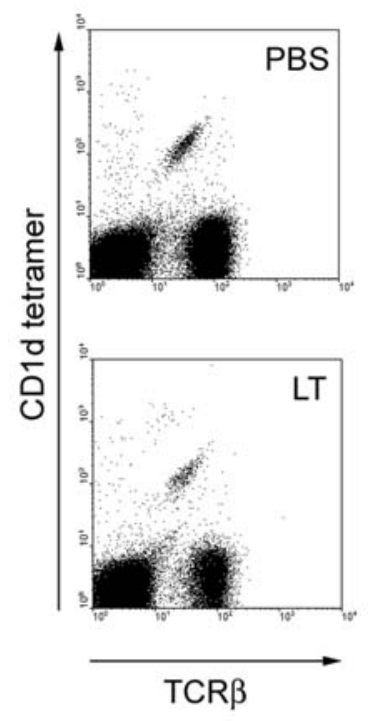

PBS

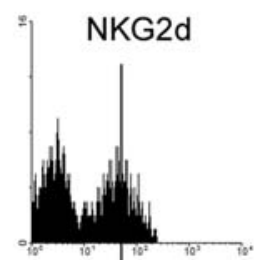

LT
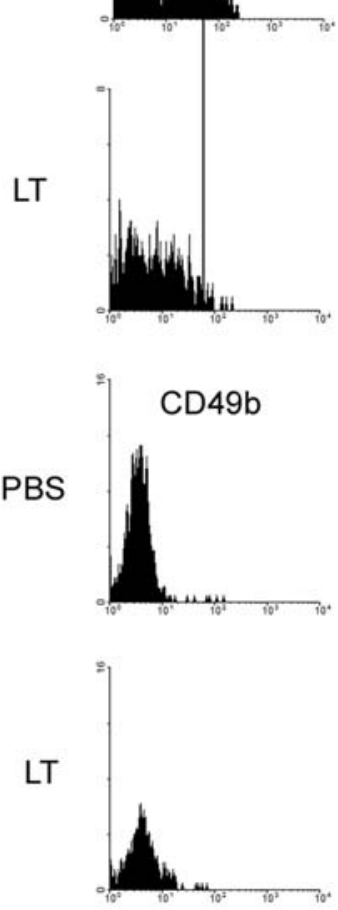
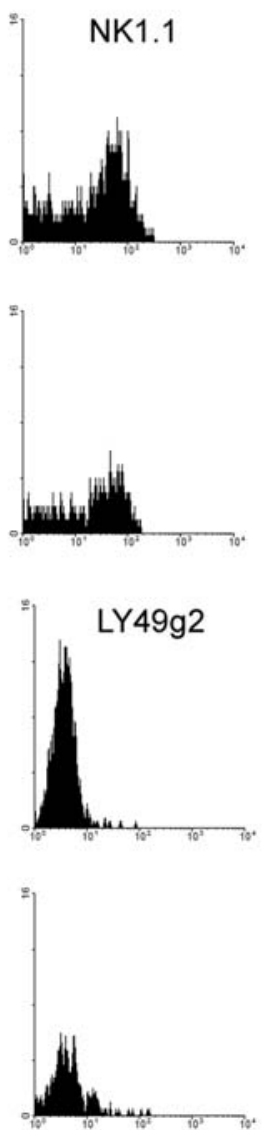

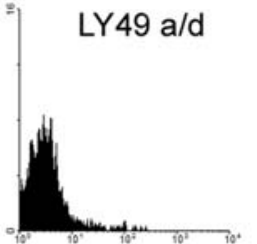

LY49 c/i/f/h
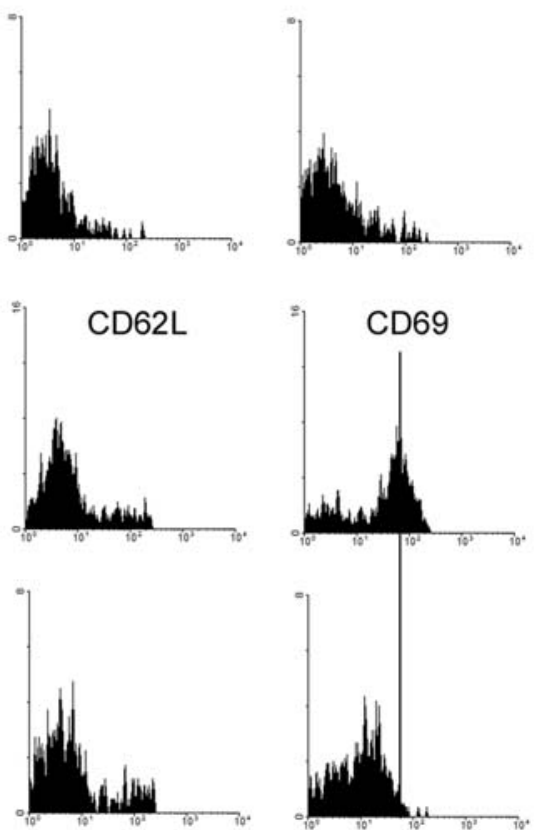

Figure 2. LT alters expression of selected NKT cell surface markers. C57BL/6 were treated with $100 \mu \mathrm{g}$ of LT in PBS by the i.v. route or mocktreated with PBS alone. After $96 \mathrm{~h}$, splenocytes were obtained and incubated with FcR-blocking mAb 2.4G2 in the presence of $\alpha$-GC/CD1d tetramer, anti-TCR $\beta \mathrm{mAb}$ and $\mathrm{mAbs}$ as indicated. Cells were then washed, fixed and analyzed by flow cytometry. A Shows $\alpha-\mathrm{GC} / \mathrm{CD} 1 \mathrm{~d}$ tetramer ${ }^{+} / \mathrm{TCR} \beta^{+}$NKT cells B Histograms show expression of indicated markers after gating on NKT cells. Data are representative of 3 independent experiments.

doi:10.1371/journal.ppat.1000588.g002

causes NKT non-responsiveness to antigenic stimulation [15]. These results suggest that the sub-lethal dose of toxin administered in our study does not result in cell death, apoptosis or PD-1dependent anergy in NKT cells and reinforces the concept that the mechanisms of anergy induction by BCG, LPS, $\alpha-G C$ and LT are different from each other.

It is possible that our method of gating on live lymphocytes by FSC/SSC profile excludes cells that have been killed by LT. We therefore gated on $\mathrm{FSC}^{\mathrm{lo}} / \mathrm{SSC}^{\mathrm{hi}}$ cells and assessed the effect of toxin on the number of 'dead' cells as well as the frequency of $\alpha$ GC/CDld tetramer-binding cells and their Annexin V binding and 7-AAD uptake (Figure S4). LT had very little effect on the number of non-viable cells recovered but there was considerable non-specific binding of tetramer to those dead cells. As expected those cells were either $\mathrm{AnnV}^{+} / 7-\mathrm{AAD}^{+}$or $\mathrm{AnnV}^{-} / 7-\mathrm{AAD}^{+}$and thus non-viable. Therefore while LT is likely to result in NKT necrosis in vivo, those cells are likely cleared from the spleen and live non-apoptotic cells are recovered in our assays.

\section{LT inhibits CD1d/ $\alpha$-GC-stimulated cytokine production}

LT induced an inactivated but not an apoptotic phenotype. We therefore determined if prior toxin treatment affected TCRmediated NKT activation (Figure 4). We obtained splenocytes from PBS- and LT-treated mice and stimulated them in vitro with $\alpha$-GC. We observed that LT-treated mice had a substantially reduced production of IL-4 and IFN $\gamma$ following toxin treatment (Figure 4A). While this experiment showed that LT treatment reduced the ability of NKT cells to be activated by $\alpha-G C$, it did not determine whether the LT was acting on APCs in the mixed splenocyte culture or the NKT cells or both. Published reports show that DCs, macrophages, B cells and Th cells can all be targeted by anthrax toxins $[16,17,18,26]$, and thus it is conceivable that the target of LT in these cultures is the APC. To address this issue we separately exposed the NKT cells and the APCs $\left(J \propto 18^{-1-}\right.$ splenocytes) to LT, washed the cells and then cultured them separately or together with and without $\alpha$-GC (Figure $4 \mathrm{~B})$. For this approach we obtained splenocytes from Type I ( $\alpha$-GC-reactive) NKT-deficient $\mathrm{J} \alpha 18^{-/-}$mice and in vitro-expanded NKT cells derived from C57BL/6 splenocytes. We treated J $\alpha 18^{-/-}$ splenocytes and NKT cells with PBS or LT before washing and then co-cultured the cells with or without $\alpha$-GG (Figure 4B). We observed that IL-4 production was not affected, but IFN $\gamma$ production was inhibited when the NKT cells but not the J $\alpha 18^{-/-}$splenocytes that were treated with LT. The reason for the lack of inhibition of IL-4 production in Figure 4B is not clear, but may be attributable to the behavior of the in vitro-expanded NKT cells as compared to the whole C57BL/ 6 splenocyte cultures. It is possible that the Th1/Th2 balance in ex vivo-expanded NKT cells is more readily disrupted following toxin treatment than in NKT cells in freshly harvested mixed splenocytes. 

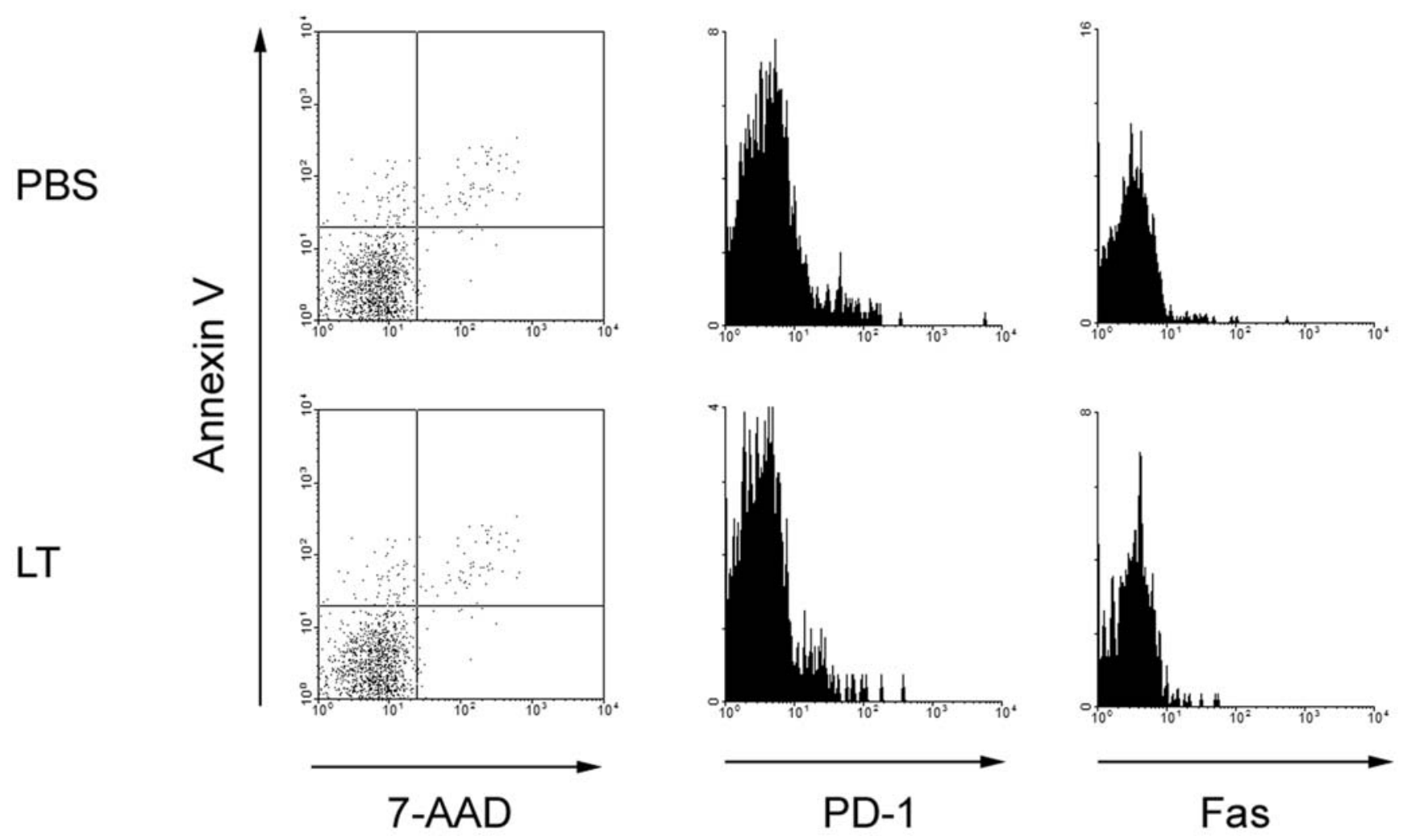

Figure 3. NKT cells from toxin-treated mice are viable and non-apoptotic. C57BL/6 were treated with $100 \mu \mathrm{g}$ of LT in PBS by the i.v. route or mock-treated with PBS alone. After $4 \mathrm{~d}$, splenocytes were obtained and incubated with FcR-blocking mAb 2.4G2 in the presence of CD1d tetramer and anti-TCR $\beta$ mAb and $\mathrm{mAb}$ or reagents indicated. After washing and fixation, cells were analyzed by flow cytometry. Data are representative of 3 independent experiments and show uptake of 7-AAD and expression of Annexin V, PD-1 and Fas by $\alpha-G C / C D 1 d$ tetramer ${ }^{+} / T C R \beta^{+}$cells. doi:10.1371/journal.ppat.1000588.g003

We also confirmed that the effect of LT on NKT cytokine production required active $\mathrm{LF}$ (Figure 4G). Mice were treated in vivo with $\mathrm{PBS}$, the non-functional mutant $\mathrm{PA}+\mathrm{LF}^{\mathrm{H} 690 \mathrm{C}}$, or active LT before enriching NKT cells and stimulating them in vitro with anti-CD3 and CD28 mAbs. We observed that only the active toxin was able to suppress cytokine production by the NKT cells. It should be noted that the method used for NKT stimulation in Figure 4C (CD3 and CD28 cross-linking rather than stimulation with $\alpha-\mathrm{GC}$ ), may have resulted in activation of Type I ( $\alpha$-GCreactive) and Type II ( $\alpha$-GC-non-reactive) NKT cells. However, flow cytometric analysis revealed that $80-88 \%$ of the NK $1.1^{+}$/ TCR $\beta^{+}$cells in the NKT preparation were $\alpha$-GC/CDld tetramer-binding and therefore Type I NKT cells. These data therefore show by different methods of NKT isolation, culture and stimulation, that LT has a direct effect on NKT function with respect to cytokine production.

\section{LT inhibits TCR signaling in NKT cells}

The MAPKK enzyme MEK-2 is proteolytically cleaved at the $\mathrm{N}$-terminus by lethal factor that has gained entry to TEM-8- and CMG-2-expressing cells [20]. Phosphorylation of Erk (extracellular signal-regulated protein kinase) downstream of MEK-2 is a critical component of TCR-signaling-induced cytokine transcription [27]. We therefore performed experiments to determine if the lack of GDld/ $\alpha$-GC-inducible cytokine was attributable to effects on the MAP Kinase/Erk signaling pathway. Enriched splenic NKT cells were treated with PBS or LT and then stimulated by CD3 cross-linking before preparation of cell lysates. Immunoblot analysis was conducted to examine the effect on MEK-2, and the status of TCR-induced Erk phosphorylation (Figure 5A). We used a mAb specific for the N-terminus of the MEK-2 protein which should have a decreased abundance in LT-treated cells. We observed that LT but not PA caused a loss of signal indicating Nterminal cleavage by LT. When NKT cells were treated with LT at three different doses, phosphorylation of Erk was diminished in a dose-dependent manner.

We also treated C57BL/ 6 mice with LT or PBS in vivo and then harvested splenocytes. NKT cells were isolated using $\alpha$-GC-loaded CDld tetramers and analyzed by SDS-PAGE and immunoblotting (Figure 5B). We observed that NKT cells recovered from LTtreated mice had a much lower amount of MEK-2 N-terminus than in NKT cells of PBS-treated mice. This demonstrates that LT leads to cleavage of NKT MEK-2 in vivo. We repeated this experiment, comparing the effects of PBS, the non-functional LT mutant and the wild type LT (Figure 5C). Consistent with our data in Figure 4, we observed that only the wild type LT resulted in cleavage of NKT MEK-2 in vivo.

\section{Discussion}

We demonstrated for the first time that anthrax LT had adverse effects on NKT cell function. The mechanism of action involved cleavage of MEK-2 and reduced phosphorylation of Erk. This was evidenced by reduced TCR-stimulated cytokine production. Indeed, reduced MAP kinase activation including diminished phosphorylation of Erk is evident in anergic Th cells [28,29], potentially explaining why LT induces anergy-like unresponsiveness in NKT cells stimulated via the TCR. We observed that both 

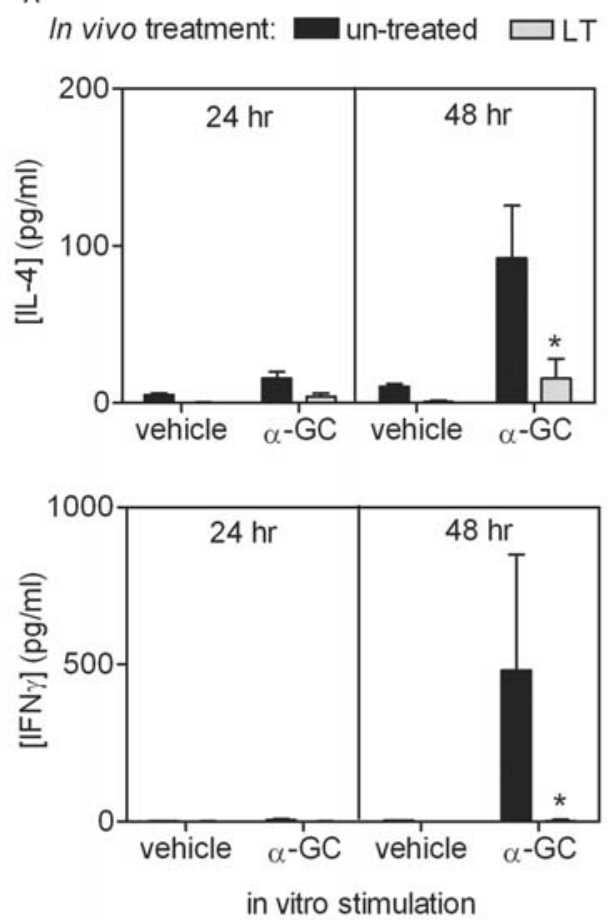

C
B
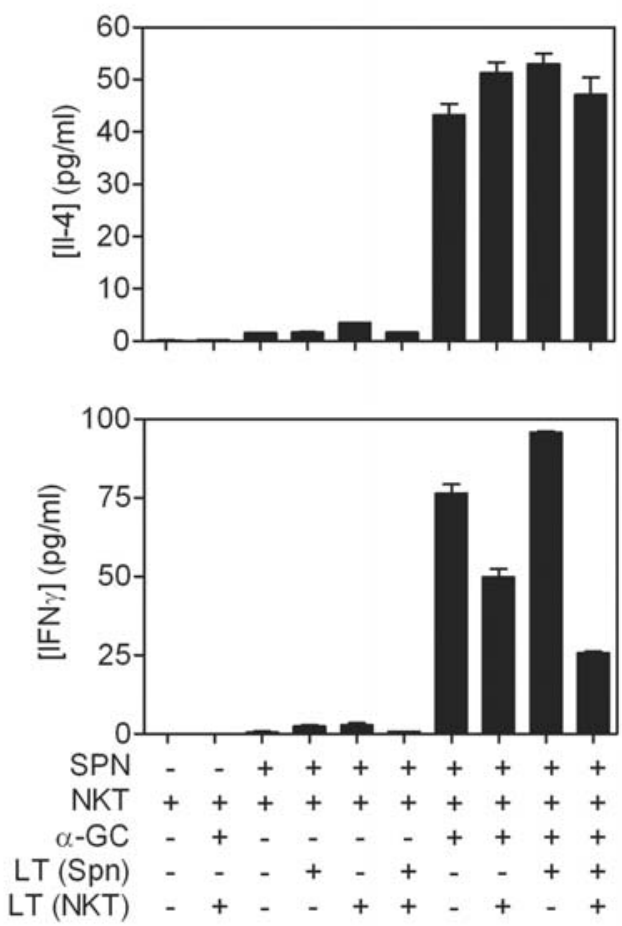

Culture Condition
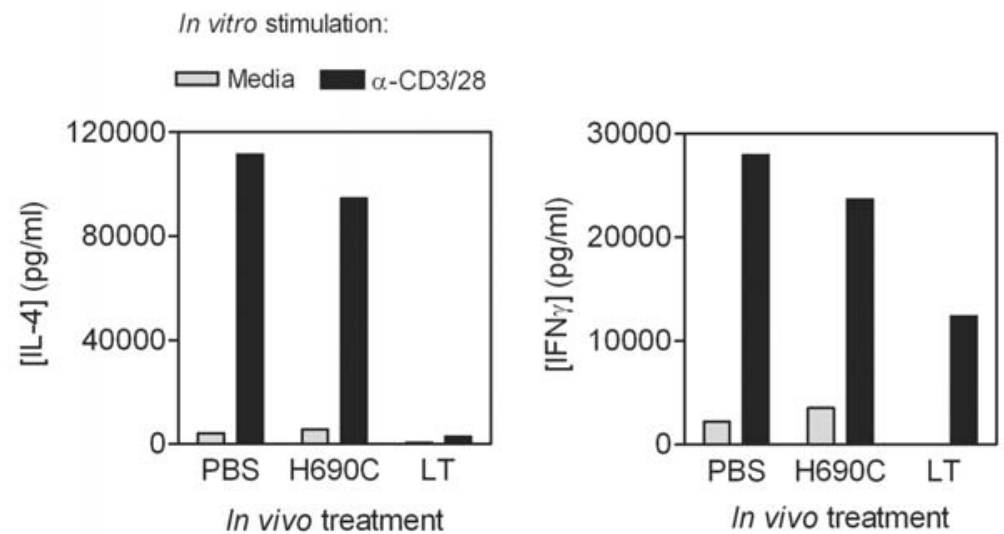

Figure 4. LT inhibits $\alpha$-GC-stimulated cytokine production. A C57BL/6 mice were treated with $100 \mu$ of LT in PBS by the i.v. route or mocktreated with PBS alone. After $4 \mathrm{~d}$, splenocytes were obtained and stimulated in vitro with $\alpha-\mathrm{GC}$ at a final concentration of $50 \mathrm{ng} / \mathrm{ml}$. Supernatants were collected after a further 24 and $48 \mathrm{~h}$ and stored at $-80^{\circ} \mathrm{C}$. B Splenocytes from J $\alpha 18^{-/-}$mice and ex vivo-expanded NKT cells from C57BL/6 mice were treated in vitro with LT at a final concentration of $1 \mu \mathrm{g} / \mathrm{ml}$ for $1 \mathrm{~h}$ before washing and culturing separately or together in the presence or absence of $\alpha-G C$ as described in A. IL-4 and IFN $\gamma$ concentrations in the supernatants were then determined by Bio-Plex analysis. Data show mean cytokine concentration for 3 mice per group \pm SD. Asterisk indicates significant difference between cytokine concentration in un-treated control and samples from LT-treated mice. C C57BL/6 mice were treated with PBS, non-functional LT mutant, or wild type LT before enrichment of NKT cells using anti-NK1.1-based magnetic isolation. Cells were stimulated with anti-CD3 and CD28 mAbs and culture supernatants collected after $48 \mathrm{~h}$. doi:10.1371/journal.ppat.1000588.g004

IFN $\gamma$ and IL-4 production was refractory to LT, with IFN $\gamma$ being inhibited to a greater extent when the TCR was directly engaged by CDld/ $\alpha-G C$. This is consistent with published findings that there is a hierarchical requirement for TCR induced MAP kinase signaling in transcription of IFN $\gamma$ and IL-4 genes by Th cells [30]. At present, it is not clear why we observe the clearest downregulation of NKG2D expression at $96 \mathrm{~h}$ post toxin treatment and apparent recovery of expression by $14 \mathrm{~d}$. Our data are likely reflective of the complex interplay of several factors including toxin delivery to NKT cells in secondary lymphoid organs; toxin entry and MEK-2 cleavage, reduced NKG2D transcription, degradation of existing NKG2D, the half life of LT in vivo, the lifespan of NKT cells and the rate of emigration of new NKT cells from the thymus during toxin-induced stress.

Although TCR-mediated activation of NKT cells was inhibited by anthrax LT, our data suggested that functional anergy may not be limited to TCR-stimulated responses. We observed a loss of NKG2D expression by NKT cells following LT treatment. The 
A

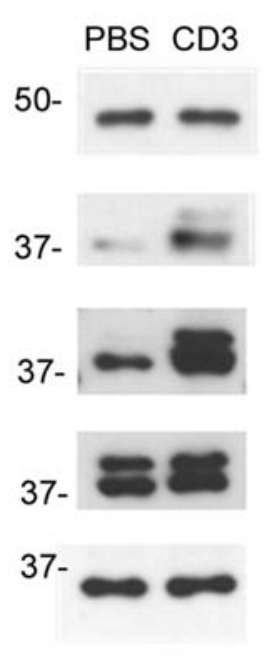

B

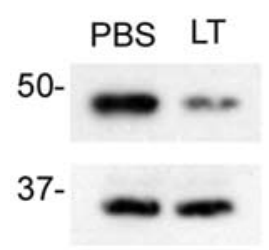

anti-CD3

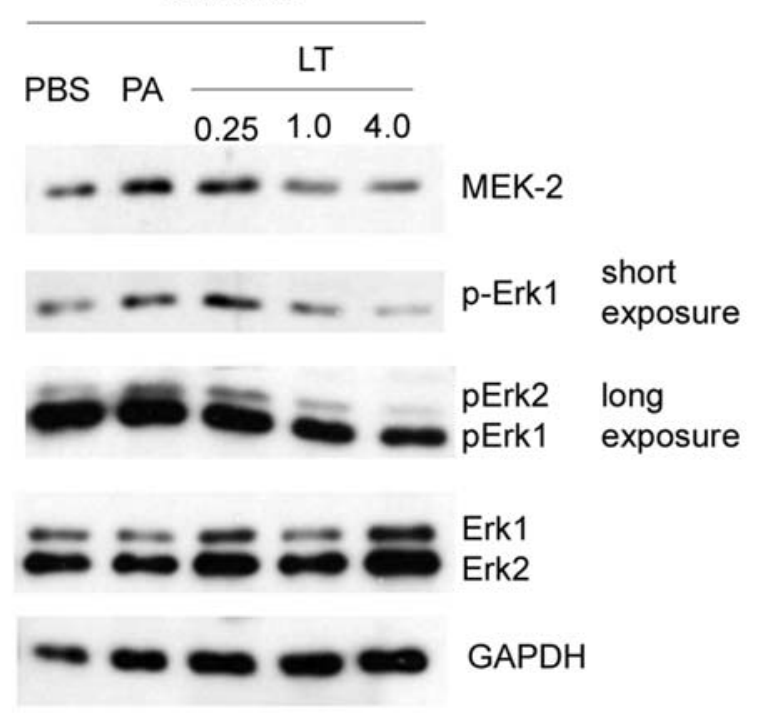

Figure 5. LT inhibits TCR-mediated signaling in NKT cells. A NKT cells were enriched from C57BL/6 splenocytes. Cells were then in vitro treated with PBS, PA $(4 \mu \mathrm{g} / \mathrm{ml})$ or LT $(0.25 \mu \mathrm{g} / \mathrm{ml}$ of PA plus $0.25 \mu \mathrm{g} / \mathrm{ml}$ of LF), or $1.0 \mu \mathrm{g} / \mathrm{ml}$ or $4 \mu \mathrm{g} / \mathrm{ml}$ of each protein, and then stimulated by cross-linking CD3. Cell lysates were prepared and resolved by SDS-PAGE and transferred to nitrocellulose membrane before immunoblotting for MEK-2 N-terminus, phospho-Erk, total Erk, and the GAPDH loading control. Left panels show un-stimulated versus stimulated controls. Right panels show samples where CD3 was cross-linked. Two exposure times are indicated for phospho-Erk (short $=10 \mathrm{~s}$, long $=90 \mathrm{~s}$ ). B C57BI/6 were treated with LT in vivo as described in materials and methods before collecting splenocytes and using CD1d-tetramers in conjunction with magnetic beads to obtain highly purified NKT cells. Lysates were prepared and subjected to SDS-PAGE and immunoblot analysis as indicated. C Experiment in B was repeated except that mice were treated with PBS, non-functional LT mutant, or wild type LT and NKT cells were obtained using the anti-NK1.1 enrichment method.

doi:10.1371/journal.ppat.1000588.g005

consistent down-regulation of NKG2D by NKT cells but not NK cells suggests that LT-treated NKT cells will be less responsive to ligation of killer-activatory receptors. At present, the implication for overall NKT function is not clear because information on the role of "NK receptors" on NKT cells is limited. NKG2D" type II NKT cells (CDld-restricted, non-reactive to $\rho-G C$ ) mediate damaging IFN $\gamma$-dependent immune responses to hepatitis B virus [31]. It is possible that the Type I NKT cells studied herein and expressing NKG2D have similar functions, leading to release of cytokines including IFN $\gamma$. It is also suggested that NKG2D could act as a TCR co-receptor and therefore be required for optimal cytokine production stimulated by $\mathrm{CDld} / \alpha-\mathrm{GC}$ complexes [32]. The mechanism by which NKG2D expression is down-regulated is similarly unclear, but may be due to inhibition of the MAP Kinase pathway. Cross-linking of NK cell NKG2D leads to Erk phosphorylation and activation of MAP kinase-dependent cytotoxicity toward target cells [33]. It is possible that the MAP kinase signaling pathway governs expression of NKG2D by NKT cells. Further examination of this issue is warranted.

While anthrax LT can undoubtedly kill a proportion of a target cell population, in several studies, live toxin-treated cells are recovered and found to be functionally impaired $[16,17,18]$. This was observed for NKT cells whereby live, anergic cells were recovered that did not stain with Annexin $\mathrm{V}$ or with 7-AAD indicating that they were neither apoptotic or necrotic. Similarly, other indicators of apoptosis such as increased FAS expression were not detected. Most interesting, though is the observation that PD-1 was not increased on LT-treated NKT cells. PD-1 has been shown in a series of recent papers $[25,34,35,36]$ to be an important mediator of NKT anergy, whereby PD-1 blockade can prevent anergy or CD28 ligation can reverse the effects of $\alpha$-GC-induced anergy $[25,36]$. As indicated by our results, the anergy induced by LPS, $\alpha$-GC and by anthrax LT may all be different, indicating that researchers will need to consider a broader array of NKT function in ascribing "anergy" to the functional status of an NKT cell.

Our data demonstrate that NKT cells are potentially a more significant target of the anthrax LT than other immune cell types because they express higher amounts of the TEM-8 and CMG-2 receptors (Figure 1). However, these data do not reveal if NKT cells are more significant targets during anthrax infection. We have observed that NKT cells and $\mathrm{CD}^{+} \mathrm{T}$ cells are similarly susceptible to LT in vivo and in vitro using the assays described 
herein (data not shown). This suggests the higher amounts of PA receptor on NKT cells as compared to $\mathrm{CD}^{+} \mathrm{T}$ cells may only determine susceptibility to LT when there are very low amounts of LT at the earliest stages of infection. Alternatively, $\mathrm{CD}^{+}{ }^{+} \mathrm{T}$ cells and NKT cells may both express great enough numbers of PA receptors to allow MEK-2 cleavage sufficient to prevent TCRinduced cytokine production in both cell types. Efforts are underway to assess the relative impact of LT on NKT cells as compared to other immune cell types. Regardless of whether anthrax LT affects one immune cell type more than another the sustained deleterious effects of toxins on B cells, DC, Th and NKT cells is likely to suppress the initiation of the adaptive immune response and reduce the ability of the host to clear the pathogen. Further study will focus on the implications of an LT insult on subsequent NKT adaptive immune responses to a pathogen challenge.

\section{Supporting Information}

Figure S1 Effect of LT on splenic weight, cell count and NKT frequency. C57BL/ 6 mice were treated with $100 \mu \mathrm{g}$ of LT in PBS by the i.v. route or mock-treated with PBS alone. (A) After $4 \mathrm{~d}$, spleens were obtained and weighed before isolation of splenocytes which were then enumerated. (B) In a separate experiment, splenocytes were incubated with FcR-blocking mAb 2.4G2 in the presence of $\alpha$-GC/CDld tetramer and anti-TCR $\beta \mathrm{mAb}$ and analyzed by flow cytometry.

Found at: doi:10.1371/journal.ppat.1000588.s001 (0.10 MB TIF)

Figure S2 Down regulation of NKG2D expression is NKT specific and requires active toxin. (A) C57BL/6 and $\mathrm{J} \alpha 18^{-/-}$mice were treated with $100 \mu \mathrm{g}$ of LT in PBS by the $i . v$. route or mocktreated with PBS alone. After $4 \mathrm{~d}$, splenocytes were obtained and incubated with FcR-blocking mAb 2.4G2 in the presence of CD1d tetramer, anti-TCR $\beta$ and anti-NKG2D mAb (C57BL/6) or antiNK1.1, anti-TCR $\beta$ and anti-NKG2D mAbs $\left(\mathrm{J} 18^{-/-}\right)$. Cells were then washed, fixed and analyzed by flow cytometry. (B) C57BL/6 mice were treated as in $(\mathrm{A})$ except that $\mathrm{LF}^{\mathrm{H} 690 \mathrm{C}}$ inactive mutant

\section{References}

1. Taniguchi M, Harada M, Kojo S, Nakayama T, Wakao H (2003) The regulatory role of Valpha14 NKT cells in innate and acquired immune response. Annu Rev Immunol 21: 483-513.

2. Galli G, Pittoni P, Tonti E, Malzone G, Uematsu Y, et al. (2007) Invariant NKT cells sustain specific B cell responses and memory. Proc Natl Acad Sci U S A 104: 3984-3989.

3. Devera TS, Shah HB, Lang GA, Lang ML (2008) Glycolipid-activated NKT cells support the induction of persistent plasma cell responses and antibody titers. Eur J Immunol 38: 1001-1011.

4. Hermans IF, Silk JD, Gileadi U, Salio M, Mathew B, et al. (2003) NKT cells enhance CD4+ and CD8+ $\mathrm{T}$ cell responses to soluble antigen in vivo through direct interaction with dendritic cells. J Immunol 171: 5140-5147.

5. Lang GA, Devera TS, Lang ML (2008) Requirement for CDld expression by B cells to stimulate NKT cell-enhanced antibody production. Blood 111: 2158-2162.

6. Tonti E, Galli G, Malzone C, Abrignani S, Casorati G, et al. (2009) NKT-cell help to B lymphocytes can occur independently of cognate interaction. Blood 113: $370-376$.

7. Leadbetter EA, Brigl M, Illarionov P, Cohen N, Luteran MC, et al. (2008) NK T cells provide lipid antigen-specific cognate help for B cells. Proc Natl Acad Sci U S A 105: 8339-8344.

8. Fujii S, Liu K, Smith C, Bonito AJ, Steinman RM (2004) The linkage of innate to adaptive immunity via maturing dendritic cells in vivo requires CD40 ligation in addition to antigen presentation and CD80/86 costimulation. J Exp Med 199: $1607-1618$.

9. Fujii S, Shimizu K, Smith G, Bonifaz L, Steinman RM (2003) Activation of natural killer $\mathrm{T}$ cells by alpha-galactosylceramide rapidly induces the full maturation of dendritic cells in vivo and thereby acts as an adjuvant for combined CD4 and CD8 T cell immunity to a coadministered protein. J Exp Med 198: 267-279.

10. Fujii S, Shimizu K, Kronenberg M, Steinman RM (2002) Prolonged IFNgamma-producing NKT response induced with alpha-galactosylceramideloaded DCs. Nat Immunol 3: 867-874. was administered. Data shows expression of NKG2D by CDld tetramer ${ }^{+} / \mathrm{TCR}^{+}$cells.

Found at: doi:10.1371/journal.ppat.1000588.s002 (0.10 MB TIF)

Figure S3 Effect of LT on NKT expression of NKG2D at early and late time points. C57BL/6 mice were treated with $100 \mu \mathrm{g}$ of LT in PBS by the i.v. route or mock-treated with PBS alone. After times indicated (A) splenocytes (B) LN cells and (C) thymocytes were obtained and incubated with FcR-blocking mAb 2.4G2 in the presence of $\alpha$-GC/CDld tetramer, anti-TCR $\beta$ mAb and antiNKG2D mAb. Cells were analyzed by flow cytometry.

Found at: doi:10.1371/journal.ppat.1000588.s003 (0.27 MB TIF)

Figure S4 LT has minimal effect on frequency and number of non-viable NKT cells in isolated splenocyte samples. The same samples described in Figure 3 were re-analyzed this time gating on $\mathrm{FSC}^{\mathrm{lo}} / \mathrm{SSC}^{\text {hi }}$ cells (density plot, left panel) and then gating on all $\alpha$-GC/CDld tetramer-binding cells (dot plot, middle panels) followed by analysis of Annexin $\mathrm{V}$ and 7-AAD staining (dot plot, right panels).

Found at: doi:10.1371/journal.ppat.1000588.s004 (0.17 MB TIF)

\section{Acknowledgments}

We acknowledge generous support from the NIAID Tetramer Facility (Emory University, Atlanta, GA) for supplying CDld tetramers. We thank Dr. J. Collier (Harvard Medical School, Boston, MA) for the PA- and LFencoding plasmids. We are grateful to Dr. M. Kronenberg of the La Jolla Institute for Allergy and Immunology (La Jolla, CA) for the kind gift of the $\mathrm{J} \alpha 18^{-/-}$mice and to Dr. M. Taniguchi of the RIKEN Institute (Riken, Japan) for providing permission to obtain and use the mice. We thank Dr. M. Coggeshall and Dr. J. Capra (President Emeritus) of the Oklahoma Medical Research Foundation (Oklahoma City, OK) for reviewing the manuscript prior to submission and providing helpful suggestions.

\section{Author Contributions}

Conceived and designed the experiments: SKJ GAL JDB MLL. Performed the experiments: SKJ GAL JLL TSD LMA HBS MLL. Analyzed the data: SKJ GAL JDB MLL. Contributed reagents/materials/analysis tools: JDB. Wrote the paper: SKJ GAL JDB MLL.

11. Belperron AA, Dailey CM, Bockenstedt LK (2005) Infection-induced marginal zone $\mathrm{B}$ cell production of Borrelia hermsii-specific antibody is impaired in the absence of CD1d. J Immunol 174: 5681-5686.

12. Kumar H, Belperron A, Barthold SW, Bockenstedt LK (2000) Cutting edge: CDld deficiency impairs murine host defense against the spirochete, Borrelia burgdorferi. J Immunol 165: 4797-4801

13. Ko SY, Ko HJ, Chang WS, Park SH, Kweon MN, et al. (2005) alphaGalactosylceramide can act as a nasal vaccine adjuvant inducing protective immune responses against viral infection and tumor. J Immunol 175: 3309-3317.

14. Parekh VV, Wilson MT, Olivares-Villagomez D, Singh AK, Wu L, et al. (2005) Glycolipid antigen induces long-term natural killer $\mathrm{T}$ cell anergy in mice. J Clin Invest 115: 2572-2583.

15. Chiba A, Dascher CC, Besra GS, Brenner MB (2008) Rapid NKT cell responses are self-terminating during the course of microbial infection. J Immunol 181: 2292-2302.

16. Agrawal A, Lingappa J, Leppla SH, Agrawal S, Jabbar A, et al. (2003) Impairment of dendritic cells and adaptive immunity by anthrax lethal toxin. Nature 424: 329-334.

17. Fang H, Xu L, Chen TY, Cyr JM, Frucht DM (2006) Anthrax lethal toxin has direct and potent inhibitory effects on $\mathrm{B}$ cell proliferation and immunoglobulin production. J Immunol 176: 6155-6161.

18. Paccani SR, Tonello F, Ghittoni R, Natale M, Muraro L, et al. (2005) Anthrax toxins suppress $\mathrm{T}$ lymphocyte activation by disrupting antigen receptor signaling. J Exp Med 201: 325-331.

19. Collier RJ, YoungJA (2003) Anthrax toxin. Annu Rev Cell Dev Biol 19: 45-70.

20. Bardwell AJ, Abdollahi M, Bardwell L (2004) Anthrax lethal factor-cleavage products of MAPK (mitogen-activated protein kinase) kinases exhibit reduced binding to their cognate MAPKs. Biochem J 378: 569-577.

21. Salles, II, Voth DE, Ward SC, Averette KM, Tweten RK, et al. (2006) Cytotoxic activity of Bacillus anthracis protective antigen observed in a macrophage cell line overexpressing ANTXR1. Cell Microbiol 8: 1272-1281. 
22. Watarai H, Nakagawa R, Omori-Miyake M, Dashtsoodol N, Taniguchi M (2008) Methods for detection, isolation and culture of mouse and human invariant NKT cells. Nat Protoc 3: 70-78.

23. Scobie HM, Thomas D, Marlett JM, Destito G, Wigelsworth DJ, et al. (2005) A soluble receptor decoy protects rats against anthrax lethal toxin challenge. J Infect Dis 192: 1047-1051.

24. van Der Vliet HJ, Nishi N, de Gruijl TD, von Blomberg BM, van den Eertwegh AJ, et al. (2000) Human natural killer T cells acquire a memoryactivated phenotype before birth. Blood 95: 2440-2442.

25. Parekh VV, Lalani S, Kim S, Halder R, Azuma M, et al (2009) PD-1/PD-L blockade prevents anergy induction and enhances the anti-tumor activities of glycolipid-activated invariant NKT cells. J Immunol 182: 2816-2826.

26. Agrawal A, Pulendran B (2004) Anthrax lethal toxin: a weapon of multisystem destruction. Cell Mol Life Sci 61: 2859-2865.

27. Dong C, Davis RJ, Flavell RA (2002) MAP kinases in the immune response. Annu Rev Immunol 20: 55-72.

28. Li W, Whaley CD, Mondino A, Mueller DL (1996) Blocked signal transduction to the ERK and JNK protein kinases in anergic CD4+ T cells. Science 271: $1272-1276$.

29. Adams CL, Grierson AM, Mowat AM, Harnett MM, Garside P (2004) Differences in the kinetics, amplitude, and localization of ERK activation in anergy and priming revealed at the level of individual primary $\mathrm{T}$ cells by laser scanning cytometry. J Immunol 173: 1579-1586.
30. Egerton M, Fitzpatrick DR, Catling AD, Kelso A (1996) Differential activation of $\mathrm{T}$ cell cytokine production by the extracellular signal-regulated kinase (ERK) signaling pathway. Eur J Immunol 26: 2279-2285.

31. Vilarinho S, Ogasawara K, Nishimura S, Lanier LL, Baron JL (2007) Blockade of NKG2D on NKT cells prevents hepatitis and the acute immune response to hepatitis B virus. Proc Natl Acad Sci U S A 104: 18187-18192.

32. Vivier E, Tomasello E, Paul P (2002) Lymphocyte activation via NKG2D: towards a new paradigm in immune recognition? Curr Opin Immunol 14: 306-311.

33. Li C, Ge B, Nicotra M, Stern JN, Kopcow HD, et al. (2008) JNK MAP kinase activation is required for MTOC and granule polarization in NKG2D-mediated NK cell cytotoxicity. Proc Natl Acad Sci U S A 105: 3017-3022.

34. Chang WS, Kim JY, Kim YJ, Kim YS, Lee JM, et al. (2008) Cutting edge: Programmed death-1/programmed death ligand 1 interaction regulates the induction and maintenance of invariant NKT cell anergy. J Immunol 181: 6707-6710.

35. Moll M, Kuylenstierna C, Gonzalez VD, Andersson SK, Bosnjak L, et al. (2009) Severe functional impairment and elevated PD-1 expression in CDld-restricted NKT cells retained during chronic HIV-1 infection. Eur J Immunol 39: 902-911.

36. Wang J, Cheng L, Wondimu Z, Swain M, Santamaria P, et al. (2009) Cutting edge: CD28 engagement releases antigen-activated invariant NKT cells from the inhibitory effects of PD-1. J Immunol 182: 6644-6647. 